This item was submitted to Loughborough's Research Repository by the author.

Items in Figshare are protected by copyright, with all rights reserved, unless otherwise indicated.

\title{
Results from an exploratory study to identify the factors that contribute to success for UK medical device small- and medium-sized enterprises
}

\section{PLEASE CITE THE PUBLISHED VERSION}

\section{PUBLISHER}

Professional Engineering Publishing / @ IMechE

VERSION

VoR (Version of Record)

\section{LICENCE}

CC BY-NC-ND 4.0

\section{REPOSITORY RECORD}

Hourd, Paul C., and David J. Williams. 2019. "Results from an Exploratory Study to Identify the Factors That Contribute to Success for UK Medical Device Small- and Medium-sized Enterprises”. figshare. https://hdl.handle.net/2134/4707. 
This item was submitted to Loughborough's Institutional Repository (https://dspace.lboro.ac.uk/) by the author and is made available under the following Creative Commons Licence conditions.

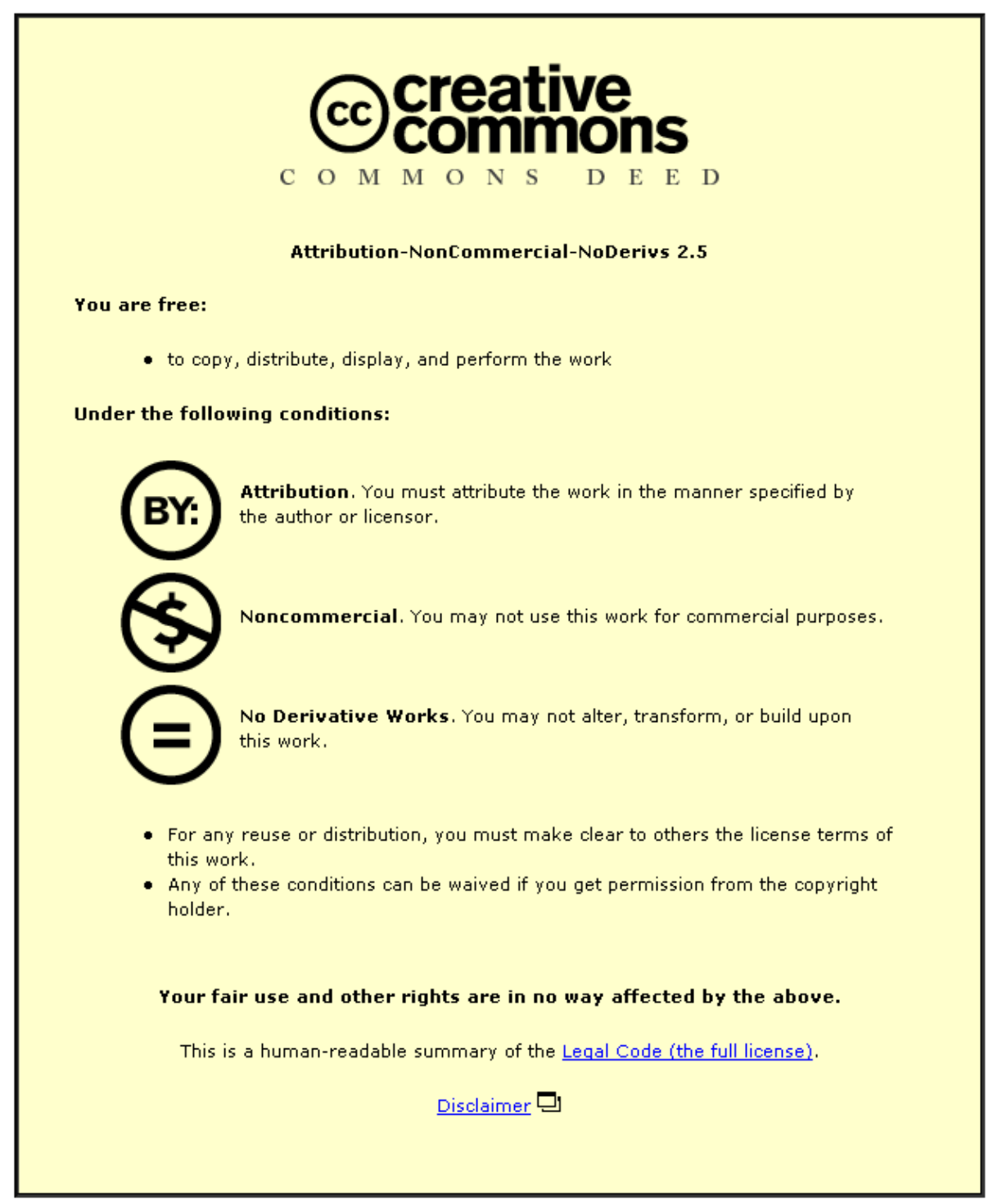

For the full text of this licence, please go to: http://creativecommons.org/licenses/by-nc-nd/2.5/ 


\title{
Results from an exploratory study to identify the factors that contribute to success for UK medical device small- and medium-sized enterprises
}

\author{
P C Hourd and D J Williams* \\ Wolfson School of Mechanical and Manufacturing Engineering, Loughborough University, Loughborough, UK
}

The manuscript was received on 8 November 2005 and was accepted after revision for publication on 3 December 2007.

DOI: 10.1243/09544119JEIM125

\begin{abstract}
This paper reports the results from an exploratory study that sets out to identify and compare the strategic approaches and patterns of business practice employed by 14 UK small- and medium-sized enterprises to achieve success in the medical device sector of the health-care industry. An interview-based survey was used to construct individual case studies of the medical device technology (MDT) companies. A cross-case analysis was performed to search for patterns and themes that cut across these individual cases. Exploratory results revealed the heterogeneity of MDT companies and the distinctive features of the MDT innovation process that emphasize the importance of a strategic approach for achieving milestones in the product development and exploitation process and for creating value for the company and its stakeholders. Recognizing the heterogeneity of MDT companies, these exploratory findings call for further investigation to understand better the influence of components of the MDT innovation process on the commercialization life cycle and value trajectory. This is required to assist start-up or spin-out MDT companies in the UK and worldwide to navigate the critical transitions that determine access to financial and consumer markets and enhance the potential to build a successful business. This will be important not only for bioscience-based companies but also for engineering-based companies aiming to convert their activities into medical devices and the health- and social-care market.
\end{abstract}

Keywords: medical device technology, small- and medium-sized enterprises, health care, success factors

\section{INTRODUCTION}

The health-care marketplace has a number of characteristics that distinguish it from those of other sectors, particularly the influence of national and international regulation, and the influence of the scale and wealth of large multinational companies on both the marketplace and the intellectual property (IP) landscape. This adds to the complexity and business risk of operating in the sector by, for example, lengthening the time required for new product development, shortening or circumventing the period of effective exploitation of patent protection, increasing the resources and investment re-

*Corresponding author: Wolfson School of Mechanical and Manufacturing Engineering, Loughborough University, Ashby Road, Loughborough, Leicestershire, LE11 3TU, UK. email: d.j.williams@lboro.ac.uk quired for manufacturing and successful product launch, and conditioning the route to market.

Within this marketplace, the medical device technology (MDT) sector, in comparison with the pharmaceutical and biotechnology sectors of the health-care industry, is highly heterogeneous, represented by companies active in the development and manufacture of a diverse range of product technologies from low-technology commodity hospital supplies such as syringes or wound dressings to higher-technology devices and capital equipment for disease screening, diagnosis, and therapy such as pacemakers, stents, or X-ray machines. The US Food and Drug Administration, in fact, recognizes about 1700 general categories of medical devices, within which there are thousands of products consisting of iterations and combinations of these device types [1]. In the UK, for example, the MDT industry is highly diversified and innovative and consist of a 
series of subsectors populated by a large number of small organizations. (The database of a leading UK trade association of companies providing medical devices and related services (Association of British Healthcare Industries) includes around $4800 \mathrm{MDT}$ companies operating in the UK. 85 per cent of health-care companies in the UK are estimated to have a turnover of less than $£ 5$ million per year. Larger UK companies have sales typically between $£ 500$ million and $£ 1$ billion or more a year, and there are also a few major foreign-owned companies, mainly US companies [2].) With the National Health Service (NHS) as the world's largest health-care delivery organization and the main UK customer for medical device products, the MDT industry in the UK plays a significant role in contributing to patient care, public health, and the national economy.

The innovation process for MDT also has many distinctive features that distinguish it from the innovation process that characterizes the pharmaceutical and biotechnology sectors of the industry. The MDT innovation process is driven by a large share of small companies that consist of both bioscience-based and engineering-based companies [3]. The innovation process is therefore underpinned by the convergence of bioscience, engineering, and manufacturing expertise from a wide variety of technology areas including electronics, mechanical engineering, polymer science, chemistry, biochemistry, as well as bioengineering, biomaterial, and textile sciences. Innovation in the MDT sector rarely moves in a linear and unidirectional pattern [4]. Instead it is often a dynamic and incremental process in which end users play a significant role in shaping its rate and direction (i.e. development does not end with the adoption of the innovation in clinical practice), with medical device manufacturers and their competitors continually developing improvements to existing devices.

Since the number of unknowns in a medical device development process are usually smaller than for the development of a new chemical compound or biological product and because of the iterative nature of many of the technologies produced, clinical trials may only be required for certain classes of device that incorporate new modes of action, or new materials or that target new indications $[\mathbf{1}, \mathbf{5}, \mathbf{6}]$. Hence the average development time (and associated cost) for medical devices (concept to commercialization) varies dramatically, ranging from 1 to 2 years for incremental devices to 5 to 7 years for radical devices, dependent on the product type, complexity, and degree of risk to the patient that dictates their regulatory defined conformance and approval route. Relatively shorter product development, product approval, and market entry times, as well as lower capital requirements, therefore distinguish many medical device innovations from the development of pharmaceuticals and biological products [7].

Hence, the demands placed on the industry are characterized by both the range of disciplines required to address them and the range of customers to be satisfied by the solution. The competitive nature of the industry, characterized by the rapid pace of innovation, the short product life cycles, and a patent position that can often be challenged or circumvented, demands a huge commitment to research and development (R\&D) and amplifies the need for a strategic approach to achieve success. For MDT companies, this dictates their business model and development profile, determines their external funding requirements, and defines the selection conditions that influence their access to consumer markets. In order to innovate in this sector, businesses need to understand how these constraints affect the development of products, their manufacture, and their successful commercialization. Moreover, MDT businesses, especially small businesses, need to understand the business and financial issues in this marketplace and the business models and strategic options that can address them to give both short- and long-term business success as they develop their products.

Critical success factors for product development companies have been the subject of much research over the last 20 years. Most of the research has focused on information technology or the product development processes in general. More recently, empirically based studies have described a range of critical success factors for biopharmaceutical companies or have sought to identify business strategies capable of producing sustainable growth for biotechnology companies [8-12]. Few firm level studies of MDT companies, however, have been carried out $[2,13-15]$. As described earlier, this may be because of the highly heterogeneous nature of the sector in which different submarkets coexist and that are characterized by products at different stages of the product life cycle. In the UK, for example, as a highly diverse sector with no cohesive structure, it has been difficult to obtain an accurate picture of its size, structure, and dynamics [16]. A study that considers the diversity and distinctive features of the MDT sector and the influence on the scientific, financial, and commercial resource requirements and time frames for MDT development would contribute to 
an understanding of the different strategic approaches for creating value in the sector.

This exploratory study engaged the leadership of UK small- and medium-sized enterprises (SMEs) operating in the MDT sector in a dialogue to gain a deeper understanding of the actions that some individual firms have undertaken to enhance their chances of success. The study aimed to compare and contrast the strategic approaches employed by successful entrepreneurs and emerging MDT companies. In the first section of the paper, a series of case studies of MDT SMEs is presented to highlight their experiences and views on forming and building a successful business. In the second section of the paper the similarities in their approach are highlighted and the factors and attributes held to cause success examined. The third section of the paper discusses the strategic approaches that MDT companies have taken to achieve successful milestones in the value trajectory and identifies areas for further work. While the present authors have placed their work in the academic management literature, they have chosen to use accessible business-oriented and business-friendly frameworks to structure the results and interpretation of their case study sample.

\section{SURVEY AND METHODOLOGY}

The study focused on companies drawn from the MDT sector, whose activities were wholly or partly focused in human health care. A convenience sample of 14 UK MDT SMEs was selected from a list of prospective companies and contacts constructed based on in-house knowledge, consultation with industry observers, trade associations, and webbased research. Data on each of these companies were drawn from an interview-based survey, consisting of non-confidential face-to-face conversational-style interviews with the senior managers of each of the 14 UK MDT companies. Data from this survey were used to construct individual case studies and cross-case analysis performed to search for patterns and themes that cut across the individual cases. These data were supplemented where possible with secondary information drawn from company reports and accounts. More than half the interviews were conducted with the chief executive officer or managing director of the company.

A straightforward semistructured questionnaire was constructed to guide the interview process with nominated companies. The questionnaire was tested by conducting pilot interviews before commencement of the survey. The entire survey was conducted between April 2004 and March 2005. The strength of this open approach has been to allow the interviewee to lead the discussion towards strategic success factors that were important to the organization rather than those that the interview team believed to be important. Where possible, business leaders who had equity or believed that they should have equity in the company (i.e. where personal and business success were coupled) were selected for interview. This was to gain a personal view from a business perspective and to ensure that the level of leadership in the business was sufficiently able to take an objective overview.

To examine the strategic approaches to the formation, development, and operation of the company the interviews sought to relate each company's business activity with its strategic actions by addressing the following time-ordered key questions. Where were the foundations of the business? What was the first success and how was it achieved? What were the company's measures of success? What were the key stages in the growth of the business? What strategic actions enhanced the company's chance of success in the marketplace? What constraints did operating in the health-care sector add to the 'normal' activities of businesses? What were the unforeseen cusps or turning points, and how did the company respond?

The semistructured interviews were conducted by two senior, well-qualified, and industry-sectorexperienced interviewers and recorded using detailed written notes. The data were collated and organized into a framework that defined a core set of categories; growth, security, marketing, people, operations, and financing. Detailed strategic actions and approaches were coded within this framework and then the categories further refined to allow a cross-case analysis to search for patterns and themes that cut across the individual cases.

Business models embrace a generic value chain that underlies all business activities. The value chain segregates company activities into technologically and economically distinct activities that it performs to do business [17]. To explore the different approaches that entrepreneurs and businesses use to achieve milestones in the value chain, a choice was made to differentiate MDT companies according to their business activity, broadly embracing the Druilhe-Garnsey [18] proposed typology for academic spin-out companies that takes into account the dynamics of the entrepreneurial process. Using external indicators collected by the questionnaire and from published data, this study has tried to 
Table 1 Characteristics of the MDT companies defined by business activity, stage of development, company size, and core activity

\begin{tabular}{lllll}
\hline Case study & Business activity & Growth stage & Company size & Core activity \\
\hline 1 & Development & II & Micro & Surface design technology for medical devices \\
2 & Development & II & Micro & Critical care diagnostic and therapeutic monitoring devices \\
3 & Development & III & Small & Material platform technology products, including prostheses \\
4 & Development & IV & Micro & Textile technology specializing in surgical implants \\
5 & Software & IV & Medium & Electronic patient record software \\
6 & Service & IV & Micro & Design and installation of clean rooms \\
7 & Product & III & Micro & Fluorescent probe technology \\
8 & Product & III & Micro & Critical care diagnostic products \\
9 & Product & IV & Medium & Tissue-engineered implant products \\
10 & Product & V & Medium & Wound-care and implant products \\
11 & Product & V & Medium & Medical and surgical fabrics \\
12 & Product & V & Micro & Medical life support equipment \\
13 & Product & IV & Small & Medical drug delivery inspection equipment \\
14 & Product & V & Medium & Automated instrumentation solutions for life sciences \\
\hline
\end{tabular}

group together companies with similar profiles in terms of their business activity. This differentiated the sample of companies into four main categories of business activity: one of the companies was involved in contract development and service provision, four companies were development companies aiming to commercialize their product or platform technology through licensing models, one was a software production company, and eight were vertically integrated product development companies engaged in prototype production, high-technology low-volume production or low-technology highvolume production.

For the purposes of this analysis and recognizing that delays, interruptions, and surges result in the variations in the timing, magnitude, duration, and rate of change in growth [19], the study has embraced a business analyst's view of the business growth cycle that defines five stages of business growth, from foundation to sale or flotation. The bioscience business growth cycle consists of the following [20]:

(a) stage I: companies in formation with seed or angel financing;

(b) stage II: start-up companies looking for private equity to establish business;

(c) stage III: rapidly growing companies with high cash requirements - initial public offering (IPO) candidates (?);

(d) stage IV: businesses with revenues edging towards profitability - probably public;

(e) stage V: profitable businesses pursuing sustainable growth.

External indicators based on published evidence, such as employment levels and profitability statements were used to assign each company loosely to one of these stages.

\section{CASE STUDIES BY CATEGORY}

The UK companies were located in England, described regionally as the Midlands (six SMEs), East (five SMEs), or South (three SMEs). All the survey participants included in the study fit the SME definition adopted by the European Commission (Commission Recommendation of 6 May 2003). For the purpose of this study, SMEs were defined as businesses with fewer than 250 employees, based on headcount only. Seven companies were micro-sized enterprises with fewer than ten full time employees (FTEs), two were small-sized enterprises (fewer than 50 FTEs), and five were medium-sized enterprises (fewer than 250 FTEs). The entire sample of companies had been established for 15 years or less. Many of the companies were not yet profitable and included two start-up companies at the beginning of their life cycle looking for private equity to establish the business, three rapidly growing companies with high cash requirements, five businesses with revenues edging towards profitability, and four profitable businesses pursuing sustainable growth. The characteristics of these companies are shown in Table 1.

The case studies described in the following section are described using a narrative style to reflect the conversational style of the interviews and the openness of views and perceptions expressed by the interviewees.

\subsection{Development companies}

For three young emerging companies the exploitation opportunity was built on the founder's previous knowledge and experience. Cases 1 and 2 were startup companies (stage II), originating from public research institutions in 1999 and 1998 respectively. 
Established earlier in 1995, case 3 was a (small-sized) more mature (stage III) and rapidly growing company. Despite recognizing the commercial potential, cases 1 and 2 struggled initially to define their business type because of the ubiquitous nature of their technology and a lack of familiarity with the medical device sector. In case 2 , this had manifested as a lack of market focus, which had inhibited their ability to raise funding. This was resolved by accessing resources from a local university business school to assist with market research. In contrast, case 3 started life as a 'back-bedroom' consultancy and their market knowledge was built on personal contacts and relationships that had been developed over a long period. In all three cases, business leaders participated in local business and social network activities to access external information and professional advice, also benefiting from the lower transaction costs bestowed by established local cluster networks. All three cases built protection into their assets and value. This took the form of IP protection (three cases) but was also supported with the protection of manufacturing know-how (case 2). Case 3 had implemented systems that made certain that know-how was shared within the company, e.g. through encouraging teamwork and retention of skilled personnel.

In case 1, the exploitable technology was developed within a major public research institute and was licensed from an independent technology transfer company. This had the advantage of providing founding investment for start-up and also helped to raise seed funding from two independent government-based funding sources. Case 2 relied on a government-backed Small Firms Merit Award for Research and Technology (SMART) and support from private individuals for start-up. Significantly, a further government-backed National Endowment for Science, Technology and the Arts award enabled the founder to switch from part-time to full-time activities. In both cases, these public grants were insufficient to provide longer-term financial security and stability, making it difficult to attract highquality personnel. Hence, cases 1 and 2 opted to remain small virtual businesses, outsourcing technology design and development activities and focusing on low cash burn in order to avoid financial exposure. In both cases this had resulted in slower than expected value creation. Exploring the local environment for sources of funding, both cases found that venture capitalists were reluctant to fund these medical device ventures because they were too small and lacked recognizable regulatory milestones in their product development cycle. In response, case 2 made a strategic decision to generate a platform device to provide a vehicle to seed devices in research markets and with clinical advocates and to provide an income stream via out-licensing to enable the development of further products. Case 1, through personal industrial connections of its leader, had built early alliances with potential exploiters of the technology. These had provided the resource and financial support to complete early pilot studies of prototypes.

In contrast, case 3 was able to use ancillary consultancy income to fund business development and their transition into an exploration company. A collaborative $R \& D$ programme supported by a joint Engineering and Physical Sciences Research Council-Department of Trade and Industry grant helped to advance the development and commercialization of their core technology. This had provided external validation of the technology and helped to secure sufficient venture capital investment to fund the second-phase technical and commercial development of its medical materials and product portfolio. In response to a change in the market that substantially elevated the potential value of one of their portfolio products, case $3 \mathrm{had}$ undergone a transition to a product company. The need to move the product closer to the market, and hence the requirement for clinical trials, triggered an organizational transition that involved the construction of multidisciplinary product development teams, the formation of a scientific advisory board, the implementation of formal project management procedures, and the recruitment of a commercial manager that understood the market. As a sign of continued success, case 3 has recently completed the installation of the first proprietary moulding system for the manufacture of the company's unique devices.

Case 4 was a mature, established (1986), and profitable development company (stage IV) focusing on exploiting and developing niche markets and providing solutions to engineering and surgical problems using textile technologies. With participation in specific health-care and industry conferences and connections formed through academic and industrial networks, the founders recognized potential medical applications for their textile technologies. Detailed research of market and clinical need identified specific opportunities and directed research and development. Resources required to develop the technology applications were harnessed through participation in collaborative product 
development projects supported by government or private research grants and SMART awards. This had helped to develop licensing partnerships with selected small manufacturing and marketing companies in order to bring products to market. A short and inexpensive development process for some product applications and a focus on niche markets meant that resource requirements were relatively low, such that value could be delivered relatively early in terms of revenue and company credibility. Building on this success, case 4 is continuing to develop technology solutions to address an increasing number of medical, as well as non-health-care-related applications. In making a strategic decision to stay small (micro), case 4 is continuously developing partnerships with key companies in customer sectors.

\subsection{Software company}

Case 5 started as a 'one-man' information technology (IT) consultancy company. The exploitation opportunity was based on an adaptation of an existing product for a new use and market, with the founder recognizing an opportunity to apply newly learned skills to new fields. As a micro-SME, the entrepreneur was able to fund expansion (headcount) through retained profit. Early market knowledge and marketing were built on personal contacts and network activities and led to exploratory work in two applications areas that proved fundamental to success for case 5 . These contracts, in both healthcare and non-health-care industry sectors, established the company as an IT consultancy business. The key to exploiting the health-care opportunity was in building early demonstrators for adopters to look at and for others to follow, coupled with the recruitment of health-care-experienced people and health-care 'champions' that were well placed in the national standardization bodies and that were well known in the industry sector.

Case 5 began to participate in specific conferences and training courses to identify potential sources of new business and to raise the profile of the company, gradually establishing the company as an expert in their field. Connections cultivated through conference participation and through the development of their own training courses (which provided a low-cost effective form of sales promotion) opened up opportunities in new technology fields and earned contracts with large bluechip organizations. These contracts provided a steady income stream but were short lived because larger competitors were able to offer better-quality compliance systems, which industry and government purchasing agencies such as the NHS required. This signalled a transition for case 5. Realizing it needed to make its software engineering process more formalized, it implemented a quality management system and ISO 9001 certification, which became an important part of the marketing platform that helped case 5 to sustain its growth.

In response to fundamental changes in the environment in which the company operated, case 5 identified two new opportunities in global e-commerce and NHS IT programmes. Recognizing that large organizations and state bodies operate routines for evaluating potential new suppliers that examine financial status, staff number, and facilities, case 5 needed to increase its headcount and to relocate to accommodation that reflected their sales offering and that would allow it to grow. This signalled the change from a niche consultancy company to both a product company and application service provider. The company restructured, strengthened the management team, relocated to new premises, and began to form alliances with global IT organizations to build up a value chain. The new corporate structure made it easier to manage and, in making it more attractive to private investor's, case 5 was able to secure business angel investment to fund its next growth stage and to prepare for an IPO.

\subsection{Service company}

Case 6 was a micro service-based profitable engineering business (stage IV), designing and installing clean rooms for multiple markets such as the pharmaceutical industry and the NHS. The exploitation opportunity was built on the founder's previous knowledge and experience in a related industry sector, recognizing an opportunity to apply learned skills in other fields. Case 6 started life as a 'backbedroom' consultancy, which provided an income stream to enable the development of its service application. Using retained profit, the entrepreneur was able to increase headcount and to relocate the business to facilities that reflected their sales offering and allowed the company to grow. To this end, the founder spent time recruiting the 'right' people; these were people with the personalities that fitted the existing company culture and that allowed the founder to focus more on fee-earning activities.

Market knowledge was built on personal contacts and relationships that had been developed over a long period. Recognizing that regulatory constraints could be an impediment, case 6 accessed external 
professional resources to gain a thorough understanding of the regulatory environment of the market for which the service offering was intended. This led to the development of a standardized service application package for individual target markets. In order to find a route to market, a demonstrator clean room facility was designed and built, providing visibility and demonstrated value to end users. This was a key activity for building an early, small customer base. Recognizing a new opportunity, this demonstrator was also used as an operational unit to provide a clean-assembly service to medical device companies and provided the stimulus for the development of a new business strand offering the installation of modular clean rooms in containers or portakabins. The lowestbidder' public sector procurement culture, however, hindered sales to the mainstream NHS market. Hence, the approach that case 6 adopted to facilitate the marketing and bidding processes and to expedite the route to market shifted to the identification and targeting of end users in overseas markets in order to showcase their value solution and to seek strategic alliances with companies who had complementary (high-margin) product capabilities.

\subsection{Young product companies}

For two young emerging product-oriented companies the exploitation opportunity was built on the founder's previous knowledge and connections. Cases 7 and 8 were rapidly growing companies (stage III), established in 2000 and 2002 respectively, but emerging via two very different routes. In case 7 , the founder acquired existing IP owned by the originating university. As a medical microsystems company, case 8 originated from a joint venture between two large organizations in the electronics and life sciences industries to exploit technology and IP developed primarily by one of the parent companies. In both cases, the starting resources included exploitable technology that was relatively mature. For case 7 , this meant that resources required to reach the market were relatively low for its lead product and it was therefore able to deliver value and to realize revenues relatively early. In case 7 , the exploitation opportunity was identified and built on a lengthy and detailed market research process by the founder. Start-up activities were sustained using ancillary consultancy income to fund business development, to acquire existing IP from a local university and to patent the technology. The founder participated in local business and social network activities to access external professional patent and legal advice. A perceived lack of stability hindered initial resource expansion but the recruitment of key business and research personnel was achieved with the offer of a small equity stake in the company. Case 7 accessed Government research grants in order to expand its product pipeline but, in contrast with case 8 , followed an organic development path, relying mostly on selffinancing following the provision of initial funding by the founder and board members.

Case 8 had the advantage of being able to secure seed investment from both parent companies, allowing it to invest in early preclinical trials in order to demonstrate value, which was to prove significant in later funding rounds. Further development of the technology continued to be outsourced, leveraging links to academic communities and academic partners to exploit complementary technologies that added value to their product portfolio. Case 8, however, needed further commercial funds to develop the technology to a point closer to market. With a strong founding team and board with relevant industrial experience and track record in place (many originating from the parent companies) and the early demonstration of value, case 8 was able to raise first-round private equity funding to continue the development of their microchipbased medical products, despite the reluctance of some venture capitalists to invest. This funding prompted a major organizational transition in terms of scale (doubling of headcount) and competency, with recruitment of a new core technical team and medical advisory board as part of its strategy to increase the commercial applications of the core technology microanalyser system. Consequently, case 8 has recently relocated to larger premises, and its ongoing success has been recognized with two prestigious innovation awards.

Both case 7 and case 8 had an explicit strategy to engage key opinion leaders (KOLs) in a number of the world's leading hospitals or research centres in the USA and Europe. These relationships were used to generate specific data that was applied to finetune the technology and also to produce reference publications that demonstrated value to potential customers and multinational marketing and distribution partners. For case 7 , the route to market was built on seeding the product in research markets in order to exemplify product performance through key research publications in journals and conferences. This built up an early small customer base and provided visibility to potential users. To increase the customer base it was necessary to identify specific 
applications in niche markets that would create value for the company. Recognizing the differences between the early and mainstream customer groups, the founder developed marketing and promotional tactics based on the differential design of product data sheets for target customer groups with different characteristics (the early adopters and the early majority). This was supported by the implementation of a direct sales distribution channel (via the internet) in order to reduce the time to establish a sustainable market position. To expedite the route to market, case 7 is now seeking strategic alliances with companies who have complementary products that are already selling into the identified niche markets. With the success of its first two products, and the recent launch of a third, case 7 has experienced increasing sales growth and growing profitability.

\subsection{Mature product companies}

Four cases (cases 9, 10, 11, and 12) were mature product-oriented companies, established between 1990 and 1996 (stages IV and V). Case 9, established in 1996 was a medium-sized profitable company that built on an existing patented wound-care product arising from academic research in the 1970s. To find a route to market it was necessary to identify specific applications that would create value for the company. Although licensed for use in humans, a lack of clinical efficacy evidence was impeding sales. In response, case 9 recruited a professional services manager with extensive knowledge of the market and focused their resources to engage end users (i.e. surgeons) in a market evaluation programme with the aim of gathering and publishing clinical efficacy data in the medical press.

With increasing UK sales growth for their first product, case 9 went through a lengthy process to identify market segments and clinical need targeted at specific niche surgical applications to avoid large competitor markets. An expansion of product development activities was focused on broadening their portfolio of market applications in both existing and new surgical fields of application. However, like case 7 , case 9 had difficulties accessing the UK NHS market because of the complicated purchasing decisions and multiple buying routes. Recognizing that the buying decisions in the NHS come from technical specialists such as surgeons, case 9 refocused their marketing strategy towards providing specific solutions to end users through the development of collaborative clinical projects. Connections with KOLs and the resulting publication and presentation of independent evidence at specific conferences were critical in attracting strategic marketing partners in a number of US and European Union (EU) target market segments. Knowledge and experience of the new fields in which the technology could be applied were, however, limited and provided the stepping point for transition to a new management team that recognized the differences between the EU and US markets. Recognition that the high-risk technology applications required regulatory approval to bring the product to market, case 9 was prompted to mobilize resources in order to increase their understanding of the regulatory environment of the market for which their product was intended. This signalled a transition in the business structure. Since having control of their manufacturing was an important strategic goal (recognized as important in the new generation of biologically based medicines [21]), this triggered the requirement for additional resources (both financial and human) to bring product manufacturing activities in house and to manage the resource impact of attaining regulatory compliance in the EU and the USA. With increasing product sales, the board was restructured to focus resources to suit the future needs of company and to prepare for launch of the company on the Alternative Investment Market (AIM) in the UK. Since flotation on the AIM, case 9 has continued to increase sales growth and to generate profits and returns to shareholders.

Cases 10 and 11 were well-established (established in 1990 and 1995 respectively) manufacturing offshoots of larger organizations. Both were mediumsized and profitable companies that had made the transition from a non-health-care business strand into medical products, adapting existing technology for a new use and market. Initially supplying lowcost commodity products to mass markets, the income stream derived from these early sales, together with the income from non-health-care business strands, provided a regular income stream for both companies. In both cases, the transition to a medical product company triggered the mobilization of internal R\&D resources to support new product development programmes in diversified market areas. Integral to these programmes was a strategy to exert leverage on established links to academic communities, end users, and connections with companies with complementary technologies, to identify new market opportunities, to build partnerships for the development of new products, and to access the necessary clinical trial and regulatory approval expertise. As a world-leading manufacturer 
of surgical suture material, case 10 has continued to increase its turnover. The recent successful completion of an early-phase UK-based clinical trial for one of its medical implant devices has marked its successful diversification into other medical device business areas.

In its early transition to health care, case 11 brought in a business development manager with extensive experience of the wound-care market to expedite its entry into the new primary care market. Expansion of the sales team and investment in new product development widened the scope of their product range and widened their national UK presence. As sales began to grow, the sales team needed to be expanded so that individual buyers (i.e. general practitioners (GPs) and nurse prescribers) in the primary care market could be targeted. This was achieved by combining its internal sales team with those of one of its collaborative partners. An increased revenue stream was used to continue new product development, focusing on niche market segments. However, like previous cases (case 7 and 9), case 11 had difficulty accessing the UK NHS market. Recognizing that the NHS was uniquely divided into a number of mini markets, resources were mobilized to obtain a clearer view of the routes to market and the individual buyer targets. The market strategy for new product introduction was to target end users in NHS hospitals (technical specialists who make the buying decisions) through the direct provision of application training. Accessing these individuals needed the support of KOLs who set the standards for product performance and usage in the relevant market (e.g. wound-care formularies). Relationships with KOLs were built by involving them in the early product evaluation or clinical trial processes. With further sales growth and diminishing non-health-care-related income, case 11 continued to develop new products and to identify exploitable opportunities through connections with suppliers. Eventually, increasing product complexity and expanding sales prompted substantial organizational transition to cope with the need for an increasing clinical skills base and production capacity.

Case 12 was a small well-established (established in 1990) and profitable micro-sized company specializing in the design and manufacture of medical life support equipment for hospitals. In the face of increasing competition, a change in leadership and leadership style led to a realignment of their business strategy towards a cost-down (unit-price) approach. This resulted in a remodelled distribution path, established via a strategic partnership with a distribution company to provide a direct and costeffective route to EU markets. Close relationships were built with small precision engineering suppliers to reduce costs and to ensure quality component supply. As a mature company with an established productive base, case 12 chose to evolve its product design and to sustain its innovative base by investing in a substantial $R \& D$ programme, ploughing their retained profit into updating and expanding its product line in order to stay ahead of the competition. To achieve this, case 12 had to learn a whole new set of product design skills, which was supported with external professional advice accessed through participation in local business and technical networks. To maintain an up-to-date understanding of potential issues and customer expectations in their target markets, a thorough understanding of the regulatory environment of the market for which the products were intended was built through establishing a good relationship and rapport with the regulator or notified body.

Case 13 was a rapidly growing provider of modular X-ray imaging technology solutions to system integrators and distributors, with part of its business strand in health care. The exploitation opportunity was built on the founder's previous knowledge and experience, which was founded on previous exposure to venture capitalists and the due diligence process. Through a similar IP prospecting process to that used by the founder of case 7 , the founder of case 13 brought together a team of commercial, technical, and academic parties to form the company and entered into exclusive arrangements to exploit IP from a local university.

The exploitation opportunity was identified and built on a lengthy and detailed market research process. It was clear that, given the market opportunity for the application of the core technology, and given the need for clinical trials, the resources required to commercialize the technology would be considerable. Rather than constructing a 'mega' business plan to attract massive amounts of money, case 13 chose to operate a stepwise development plan that exposed the application of the technology to potential customers, acquirers, and licensees (selling or exit points on the value trajectory) at various stages of the development plan. Start-up activities were sustained using ancillary consultancy and service income based on the expert knowledge of the founder. Case 13 also relied on a SMART award and support from local agency grants to complete proof-of-principle studies. At each stage of business development, time was spent on recruiting 
the 'right' people; people with the personalities that fitted the existing company culture. This was coupled to an organizational transformation that was aimed at losing some of the trappings of academic culture and increasing the credibility of the company. Their product development process was integrated with a continuous assessment of market and competitor intelligence (especially 'big business'), coupled with a thorough understanding of the regulatory environment of the market for which the 'product' was intended. The demonstrator technology was positioned in order to build up key end-user reference sites in the marketplace, providing visibility to potential partners. This led the company to design and build a range of X-ray systems for a number of applications and customers and secure strategic sales and marketing agreements with leading equipment suppliers. The company has recently successfully completed an AIM launch, demonstrating real value to equity holders.

Case 14 is a world leader in the design, development, manufacture, and integration of advanced industrial automation solutions for the life science industries. Resulting from a demerger of an existing organization, start-up was built on financial support from a number of private individuals and sustained initially using ancillary consultancy income to fund business development. The founders were experienced engineers with business knowledge and experience but were relatively unfamiliar with the bioindustry and its market. A lengthy prospecting process that built an industry and market picture led to the recognition of a specific productive opportunity. To find a route to market it was necessary to identify specific areas in the bioindustry that would create value for the company. Although the channels and lines of reporting were unclear and a great deal of time was spent talking to the wrong people, existing connections within the pharmaceutical industry, built through its consultancy role, provided initial access (a 'Trojan horse') to its target market. The recruitment of life science graduates with skills and experience in both life science and instrumentation camps was a key step in expanding its commercial function. These were people who spoke the customer's language and were able to translate customer need into product specifications. Finding these people was difficult and constituted high overheads but ultimately led to the first commercial success for case 14 .

An expanding knowledge base, built through direct industrial contacts, triggered the recognition of a specific commercial opportunity in new emerging application fields and signalled the transition to a discovery company for case 14 . The recruitment of an experienced marketing professional with a significant and intimate knowledge of the marketplace and hence the vision to see industry and market trends accelerated this transition. Supported by regulatory advice from external resources, case 14 gained a thorough understanding of the regulatory environment of the market for which the 'product' was intended. Understanding that they needed to operate within a completely different set of 'rules' from the normal technology or manufacturing business, case 14 directed its efforts towards the development of a standardized product package for its target market. Recognizing that early and visible adopters can profoundly alter the uptake of novel solutions among the followers, the founder's strategy was to place the technology with lead customers as early as possible. As an engineering company, this was a key element in understanding the expectations of their customers and ensuring that bioscience companies understood their technology. As sales grew, an apparent rise in competition triggered a change in strategy for case 14. In contrast with case 13 , which chose to increase its R\&D output, case 14 chose to compete on price, by sharpening marketing, delivery, and manufacturing activities and by protecting the IP position (prior to this, case 14 did not have the cash or position to protect IP). As the company grew to a medium-sized enterprise and with a changing commercial environment, the management structure was changed, bringing in new people with more specific experience relevant to the size of the business and the marketplace.

\section{DISCUSSION AND CONCLUSION: OBSERVATIONS OF KEY FACTORS}

The concept of success is difficult to define clearly, but the criteria that delineate success dictate the company's commercial objectives and the strategies that it implements to achieve them [22]. In this study, success has been defined in terms of milestones for successful performance. The case studies show that these had different scales of measure, encapsulated in the value creation process, such as conducting an IPO, having a product candidate commence or complete a successful clinical trial, launching a product candidate on the market, achieving significant financial turnover, or signing a major corporate partnering deal (Table 2). The scale of success for companies included in this study was defined by their business activity and by their stage of development. 
Table 2 Measure of success for case study companies

\begin{tabular}{|c|c|c|c|c|c|c|c|c|c|c|c|c|c|c|}
\hline \multicolumn{4}{|c|}{ Company characteristics } & \multicolumn{11}{|c|}{ Measures of success } \\
\hline 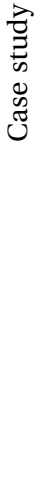 & 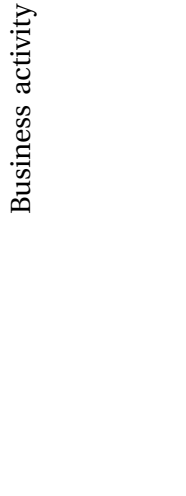 & 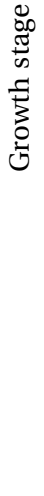 & 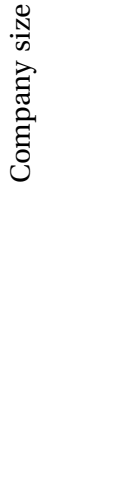 & 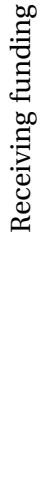 & 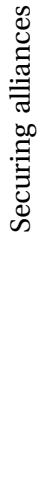 & 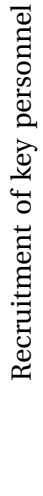 & 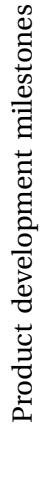 & 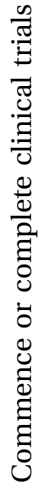 & 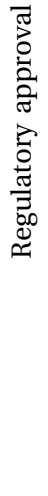 & 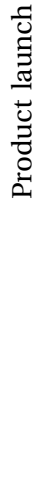 & 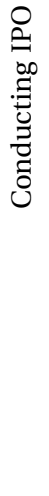 & 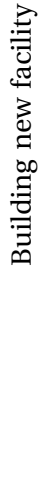 & 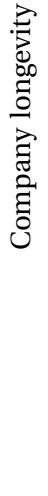 & 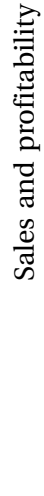 \\
\hline 2 & Development & II & Micro & ț & is & & & & & & & & & \\
\hline 3 & Development & III & Small & 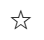 & & 约 & is & 论 & & & & & & \\
\hline 4 & Development & IV & Micro & & is & & & 论 & 论 & 约 & & & is & \\
\hline 5 & Software & IV & Medium & & $i$ & 论 & & & & 弥 & is & & ts & \\
\hline 6 & Service & IV & Micro & & tst & & ts & & & & & & & $\hat{s}$ \\
\hline 7 & Product & III & Micro & & & 约 & & & 约 & $\hat{s}$ & & & & \\
\hline 8 & Product & III & Micro & $\dot{s}$ & 谞 & 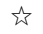 & $i$ & & & & & & & \\
\hline 9 & Product & IV & Medium & $\dot{s}$ & 访 & 拧 & & 约 & $\hat{s}$ & $\hat{i}$ & 必 & $\hat{2}$ & & \\
\hline 10 & Product & $\mathrm{V}$ & Medium & & is & & & 约 & $i s$ & th & & & & $i s$ \\
\hline 11 & Product & V & Medium & & 论 & & & 论 & & is & & & & is \\
\hline 12 & Product & V & Micro & 约 & is & & & & & $\hat{s}$ & & $\hat{s}$ & & \\
\hline 13 & Product & IV & Small & & th & & & & & & 论 & & & \\
\hline 14 & Product & $\mathrm{V}$ & Medium & & & & & & & is & 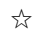 & & & $\hat{s}$ \\
\hline
\end{tabular}

In the following section, attempts are made to compare and contrast the strategic approaches that these MDT SMEs have used to create and control their sources of value. Each case study has illustrated some of the key factors that their entrepreneurs and business leaders have used to achieve milestones in their business formation, development, and operation. To simplify and guide the discussion, the responses from the interviews were synthesized into a core set of categories which were further refined into a number of broad categories defined according to the strategic elements described by the Institute of Directors (IoD) (a UK membership organization for directors responsible for company strategy) for the growth of the firm and the creation of a valuable business from a growth, profitability, and security viewpoint [23]. Figure 1 provides an overview of these strategic elements and a framework for guiding the following discussion.

\subsection{Investment in strong personnel resource}

Investment in strong personnel resource was a common theme, focused on creating a team-based, engaged, and incentivized working culture and also based on the recruitment of the right people at the right time, not just for their expertise but also for their attitude. For the more established companies (stages III to V), this was linked with an increase in scale (in terms of personnel numbers and functionality) or a change in business structure in response to the new demands that were placed on their functional elements. More than half the productdevelopment-driven companies (stages III to V), for example, had channelled their research into more standardized product and process development activities, which had driven the need for the introduction of tightly integrated cross-functional teams, disciplined project management practices, and professional managers to achieve product development or clinical trials milestones. The approach of these companies in response to the recognition of new exploitable opportunities was to build a skills base that matched the market, integrating the technology and application strands of the business, allied to the recruitment of top-level marketing personnel with an intimate knowledge of the market. For two cases, whose historical background and culture were in engineering disciplines, this was particularly important since it allowed them to establish links with the bioscience-based company network and research base, as well as the health-care marketplace. 


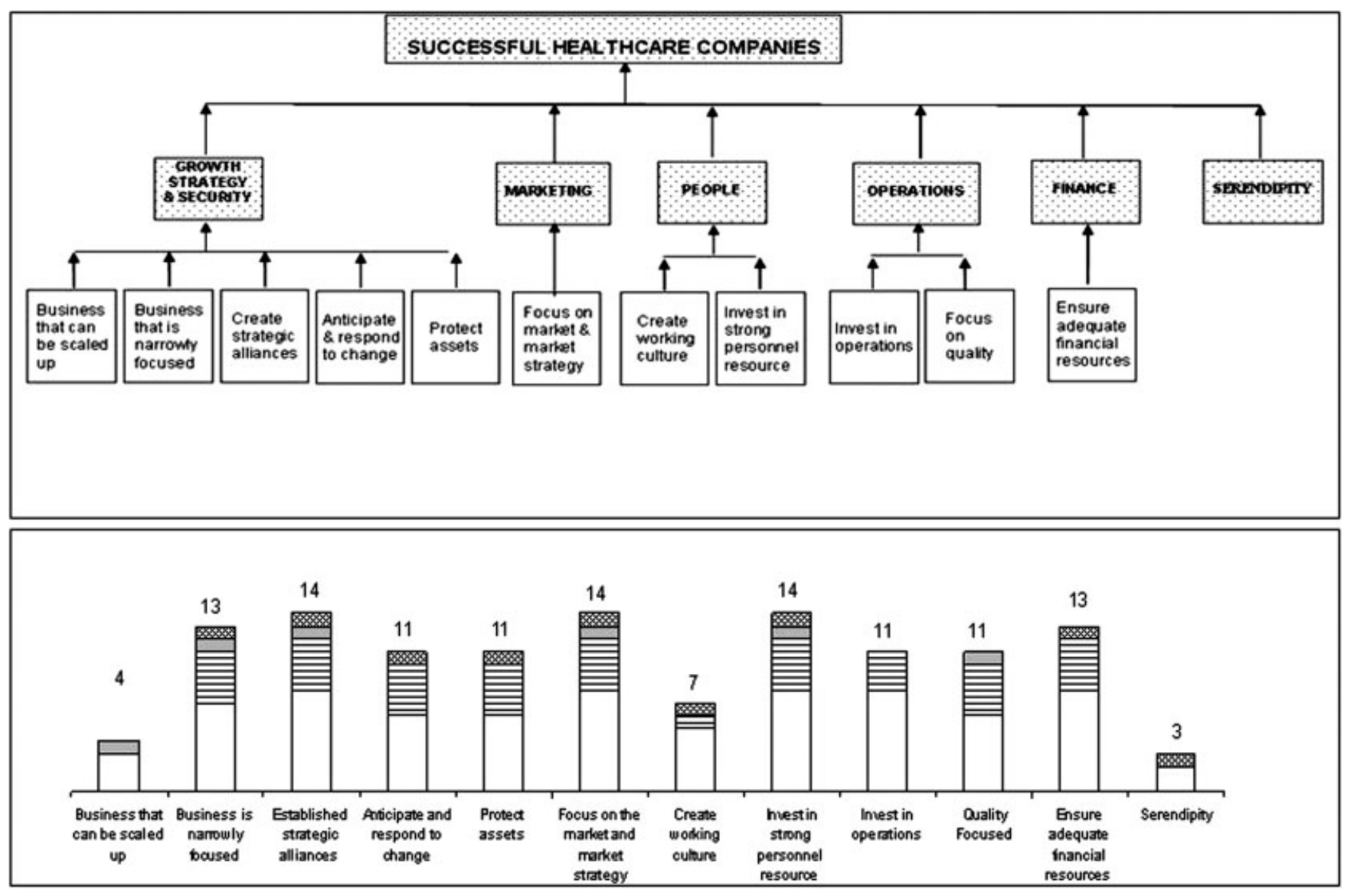

Fig. 1 Classification of case study observations: the success factor categories were classified according to the IoD framework illustrated in the top part. The lower part summarizes the number of companies (above the columns) that mentioned or emphasized specific success factors within each category during the interviews. Key for business activity: horizontal lined column, development company; grey column, service company; shaded column, software company; white column, product company

Often allied with step changes within the core management team capabilities and in the structure and dynamics of the board of directors, three quarters of the established and rapidly growing companies (stages III to V) had changed their business structure to achieve financial milestones and to overcome the changes and disruption that organizational transition brings. Signalling their organizational maturity, many of the established SMEs were led by professional managers. Except for the two product companies that had made the transition from non-health-care business strands, these established companies together with the emerging MDT development and product companies were or had been set up and led by individuals with knowledge and experience in industry. These were entrepreneurs or leaders that characteristically recognized market demand and that had a realistic view of the market. These entrepreneurs characteristically invested their own equity in the business in cash or 'sweat' (opportunity cost) and typically were able to match their intuitive knowledge of the market demand with a technological opportunity (opportunity recognition) [18]. These were people who 'see a way to make things happen and to do it' (i.e. people with vision, who embrace change, and who take and manage risk). In many cases it was the skill and vision of the entrepreneur or leader that had been a fundamental factor for success. Their individual behaviour and social capital were important, but frequently these leaders were also part of a founding team with complementary expertise that added value to the company.

\subsection{Securement of financial resources}

Many of the MDT projects that the development companies and emerging product businesses were undertaking were or had been 'bootstrapped', with entrepreneurs building on insider finance ('founder, 
family, friends, and fools'), customer contracts, bank loans, or government grants and continuously pursuing funding to raise as much money as possible even when it was not seen as essential for the subsequent growth of the company at that time. This approach tended to be strategic and opportunistic, indicative of the entrepreneur's attitude to risk taking and debt management. This compares more closely with projects in the electronic and engineering industry than with product development projects in the biotechnology and pharmaceutical sectors. Two established product companies had incorporated health-care activities in a crosssectorial product portfolio, generating income from 'old' non-health-care business strands to finance new product development. Showing characteristics of the Bullock [24] hardening model, half of the MDT companies, particularly the technology platform, equipment supply, and software SMEs had made the transition from 'soft' companies, generating early income by selling ancillary consultancy and services, to 'hard' companies that sell products. With business models directed towards building cash flow from non-equity sources these companies were able to increase productivity in the product development process. The cash flow allowed them to strengthen company infrastructure, to establish networks, to reduce the amount of time that the management team needed to spend on raising subsequent rounds of fundraising and ultimately to focus their efforts on the product development process to reduce the chances of failure. These companies had the flexibility to adopt and explore new and emerging opportunities for development, emphasized by the record of several cases that had identified and developed a number of new products.

It was evident that the sources of finance that the MDT businesses needed to access changed according to the growth stage of the company and the level of funding required. Seed financing provided a common route for converting innovative research ideas into a business proposition. Small company support schemes such as SMART grants, and the government-backed LINK programmes in the UK, for example, provided access to start-up funding for young development and product companies (stages II and III) but were generally insufficient to move the product closer to market. Nevertheless, the attitude of companies to external private finance as a route for start-up or first-round funding was mixed. Two of the development companies (cases 1 and 2), for example, experienced difficulties in accessing venture capital because, in their view, venture capitalists were reluctant to fund start-up companies, particularly because of regulatory uncertainty and the unpredictable regulatory pathways associated with the medical device sector that make the product development milestones less than clear. In response to these funding shortages, these companies chose to restrict their growth plans, to conserve their existing resources, and to seek alternative sources of funding through corporate finance or product licensing deals. This had served to lengthen the time needed to reach the next valuation point or product development milestone.

\subsection{Creation of a business that is narrowly focused}

According to the IoD, narrowly focused businesses are the most likely to create value but are also at the greatest risk of failing [23]. All but one of the MDT companies had chosen to minimize the inherent risks of technological innovation through diversification into related product areas and businesses or by outsourcing non-core activities. Development companies (stages II to IV) had chosen to reduce risk by outsourcing large components of their R\&D and product development activities. Product companies (and the service company) had increased the scope of their customer base, either by expanding into other application areas and markets for their product(s) or service or by expanding into other related product and service or business areas. This was emphasized by case 11, which had expanded their market share from the accident and emergency market to the primary care market and case 9 that had expanded product development into related therapeutic areas with a degree of research crossover (i.e. niche surgical applications). This was also highlighted in other cases in which companies had broadened product pipelines with the development of related products and services or had differentiated into non-health-care product strands.

\subsection{Establishment of strategic alliances}

Case studies revealed the prevalence of strategic partnerships in the value chain. All the MDT companies had established a network of one or (usually) more collaborations, strategic alliances (and consortia), or partnerships to exploit competencies and expertise along the value trajectory to access downstream capabilities in the areas of product development, manufacturing, clinical trials, and/or marketing and distribution. In forming 
vertical alliances with companies who had similar products, more than half the product companies (stages III to V) had expedited access to US and EU distribution channels or had facilitated expansion of sales teams. These vertical alliances were typically through licensing or joint commercialization and distribution deals with larger companies operating closer to the end user. Other key partnerships involved the use of vertical alliances to share the cost of clinical trial programmes, to augment access to manufacturing and regulatory capability, and to access complementary technologies in order to strengthen bidding processes or broaden product pipeline. Horizontal alliances were also featured, in which four of the established companies (stages IV and $V$ ) had formed alliances for the purposes of joint new product or prototype $R \& D$.

\subsection{Focus on the market and market strategy}

For product companies, the marketing process demands that they access the relevant management and marketing capabilities to establish entry into the market and to achieve these financial milestones. Rather than utilizing existing in-house resources [15], for more than half the cases (including three young companies, stages II and III) this was allied to the recruitment of senior-level marketing and sales expertise from the target market or that was well networked to the target market. However, unlike new and approved pharmaceutical products that are perhaps more likely to be accepted by the market, medical device companies involved in the development and commercialization of highly innovative and technology-intensive products faced additional marketing challenges, particularly those companies seeking to introduce technologies that cause disruption to current clinical practices. The record of three cases that had difficulties accessing the NHS highlights this point.

All the cases targeted market niches for specific applications, defined, for example, by therapeutic area within subsectors of the medical device industry, such as orthopaedic implantable devices, bandages for leg ulcers, neonatal respiratory equipment, surgical implants, and in-vitro diagnostics. More than half of these were targeting broader niche markets. In a staged strategy for new product introduction, their approach has been to demonstrate early competitive advantage in the market, based on the production of prototype demonstrators, early pilot studies in reference sites, the provision of clinical practice education and training (i.e. GP and practice nurse training for step change products). Two product companies (stages IV and V), for example, had created their broader operational base by initially targeting and establishing leadership in small segmented markets with the expressed desire to avoid competition with large competitors. A marketing strategy that focused on a leveraged approach to niche market segments or mini-markets in the mainstream market, which has typified the tactics of rapidly growing companies in other industries [25-27], had been utilized by these companies to gain visibility and credibility, to generate revenue, and to attempt to establish leadership. Significantly, the marketing and sales efforts of these companies parallel those described by Moore [27], based on his work in the hightechnology industry (in particular the IT sector), for 'crossing the chasm' into the mainstream market. Moore [27] has popularized Rogers' [25] seminal work on the diffusion of innovations, making it readily accessible to a business audience by describing an adoption life-cycle model to emphasize the importance of marketing within the high-technology industry, particularly the IT sector. According to Moore, the chasm represents the 'gulf between two distinct marketplaces for technology products'. The first marketplace consists of a group of individuals who 'are quick to appreciate the nature and benefits' of a new technology and therefore will buy the product without any prior endorsements. The other marketplace, however, contains everyone else: those people who want and will buy the new product, but only after the product has been utilized and shown to have a demonstrated value.

More than half the companies, including the development, product, and software companies, had also sought relationships and collaborations with change agents or KOLs early in their product evaluation process to open routes to the technical specialists who make the buying decisions in the NHS, i.e. surgeons, nurses, and GPs. Combined with the production of reference publications and conference participation, this served to raise the profile of the company, to validate their technology, and to improve their access to customers, to partners, and even to finance. For the product companies, in particular, the capacity to modify or reorient their market strategy was facilitated by 'probe-and-learn' processes that typify product development in the MDT industry [7]. This was emphasized by the product-oriented cases, in which adoption by practitioners in clinical practice often served as the beginning of an iterative process of refinement and 
improvement and as a precursor to selling in the early market.

Product companies, and in particular the established equipment supplier companies and the lowtechnology high-volume product companies (stages IV and V), put great emphasis on traditional components of market orientation, including protecting the market with strong customer relationships and spending time and resources on knowing and continued understanding of their customers and competitors. These companies stressed the importance of defending the threats arising from exposure to large competitors, e.g. by forming consortia or alliances or by increasing their competitive advantage in terms of clinical competencies. In order to circumvent the poor distribution systems that are often associated with medical devices, four of the product companies had implemented early distribution plans using a direct sale-and-supply strategy or, in the case of one SME, had created a separate distribution business for their own and other products that operated in parallel with their design, manufacturing, and assembly business.

\subsection{Protection of assets}

IP, usually in the form of patents, plays a major role in building sustainable advantage for many healthcare SMEs and provides positive signals of competencies for potential investors. The development companies and more than half of the product businesses recognized the importance of building protection into their assets and value. On the other hand, the technology platform companies (including services and software) did not rely on patent protection as a barrier to competition, relying instead on asset protection that took the form of protecting know-how.

\subsection{Anticipation and response to change}

Several companies demonstrated the flexibility to anticipate and respond to negative or positive external change drivers, by exploiting the opportunities or defending the threats arising from new legislative and regulatory compliance requirements, or to changes in the market. The record of case 11 , for example, that developed new products in response to implementation of British Standards in the bandage market, case 5 that restructured its business to exploit opportunities arising from a moratorium on health-care procurement of information communication technology, and case 3 that transitioned from a consultancy to an exploration company in response to a change in the market serve to highlight this point.

\subsection{Investment in operations and quality focus}

Investment in $R \& D$ and continuous innovation for new products or technology was at the forefront of all the activities of the product-oriented cases. Two of these companies had also invested in new manufacturing facilities to increase productivity. Recognizing the quality assurance focus of MDT regulatory systems and the requirements of industry customers and purchasing agencies, all the product and development companies had invested in regulatory expertise or in implementing quality systems to manage design control and regulatory compliance as a means of creating strategic competitive advantage. Monitoring the capability of their product against market need as they evolved and improved their understanding of the market was a key part of this process for matching that need.

\subsection{Serendipity}

Even for established companies, success is often the outcome of serendipity. Three of the companies (stages IV and V) admitted that luck had played a part in their success but also emphasized that they had put themselves in positions (via targeted networking) where they were most likely to find and take advantage of serendipitous events.

\section{CONCLUDING REMARKS}

Based on an exploratory study of 14 MDT companies in the UK, this paper highlights the diversity of technologies and target application markets in this sector. The challenges for the MDT companies were conditioned by their business activity, the physical and philosophical starting points of the company (i.e. academia or large industry), and the maturity of their resources. For the start-up companies, in particular, this was congruent with the findings of other empirical studies of new venture growth [18]. However, the case studies emphasize the importance of a strategic approach to achieve success in this sector, irrespective of whether the companies are new start-up development companies or mature and established product-focused companies (summarized in Fig. 2). 


\section{Growth and security}

- Diversified into related product areas and businesses or outsourced components of their R\&D and product development activities.

- Established a network of one or more collaborations, strategic alliances, or partnerships and focused on core competencies.

- Exploited opportunities or defended threats arising from new legislative and regulatory compliance requirements, or to changes in the market.

- Invested in continuous innovation and new product development.

People and organization

- Managed organizational transition within the product development cycle.

- Recruited skills and experience at the appropriate stages of company growth.

- Introduced integrated cross-functional teams, disciplined project management practices, and professional managers to achieve product development or clinical trials milestones.

- Accessed the relevant management and marketing capabilities, allied to the recruitment of senior level marketing and sales expertise from the target market.

\section{Marketing}

- Focused on a leveraged approach to niche market segments or mini-markets in the mainstream market.

- Demonstrated early competitive advantage in the market.

- Established relationships and collaborations with change agents or KOLs early in their product evaluation process.

- Participated in conferences and produced reference publications to raise the profile of the company, to validate their technology, and to improve access to customers, partners, and finance.

- Spent time and/or resources on knowing and continued understanding of their customers and competitors.

\section{Operations}

- Recognized the importance of regulatory influence on the marketplace and invested in internal or external regulatory expertise accordingly.

- Implemented quality management systems or standardized procedures.

Finance

- Raised as much cash as possible with the strategic and opportunistic pursuit of funding.

- Generated early income by selling ancillary consultancy and services, i.e. non-equity sources.

- Managed risk strategies in response to funding shortages or product setbacks.

Serendipity

- Put themselves in positions (via targeted networking) where they were most likely to find and take advantage of serendipitous events.

Fig. 2 What strategic approaches have MDT companies taken to achieve successful milestones in the value trajectory?

The study revealed that progression through the business growth life cycle is underpinned by the achievement of milestones in the product development and exploitation process that create value for the company. This strongly coupled the product development and financial cycles for these companies because value creation relied on creating prototypes or demonstrators, moving products through the clinical trial phases and obtaining regulatory approval for product launch. The business activity of the company has therefore defined how the company was resourced, the way it created 
value, and where and how value was realized in this cycle.

The attraction, retention, and incentivization of personnel and managers were key competencies exhibited by many of the MDT companies. These companies brought together the scientific innovation of researchers with the commercial expertise and social capital of managers and founders that were able to sell their ideas and eventual products to potential investors and buyers. This represented an important endowment for organizations in the early stages of their development [28]. Compatible with the findings of other empirical studies of new ventures, the case studies of the young product and development companies (stages II and III), for example, showed that the exploitation opportunity was built on the founder's previous knowledge and experience. The difficulties in defining their business type, lack of familiarity with the medical device sector, and a lack of market focus were resolved by the evolving experience of the entrepreneur and the ability to use their networking activities to mobilize resources [18].

The case studies show that, as the companies navigated the business growth cycle, their business structures changed in response to the new demands that were placed on their functional elements, such as product development, clinical trials, financial management, manufacturing, sales, and marketing. In response to the increasingly complex technical and business challenges, these companies significantly redefined the scale and structure of their skills base to exploit competencies at various transition points along the value trajectory. The business model determined the demand for organizational transition, in terms of both function and scale, as the company progressed along their product development path. For development companies, for example, the scale of this transition was different because it was not embodied in the development of a physical productive base or in manufacturing or marketing products $[\mathbf{1 8}]$. In managing the organizational transition within the product development cycle and investing in the appropriate resource competencies, the business leaders of these MDT companies had avoided significant disruptions and delays in reaching their milestones.

For the product-focused companies, the complexity of the product development process and the regulatory compliance burden established the time frame in which the company operated, the stakeholders and customers that it needed to satisfy, and the scope and scale of its value-adding activities. By lengthening the time required for new product development and increasing the investment required for manufacturing and successful product launch, the period in which these companies experienced zero product revenue and high burn rate was lengthened. This meant that the majority of product companies (i.e. those without a non-healthcare or mature product stream) relied heavily on non-financial performance indicators as a means of creating and demonstrating value before it could be captured and realized. In the case of development companies, these may be set up to commercialize a technology for licensing but may face similar challenges as they are required to move their products closer to market or aim for a transition to production [18].

In terms of value creation, all the companies had sought to establish strategic alliances throughout the value chain in order to provide the skills, competencies, and sometimes the investment to facilitate the organizational transition. However, for the product-focused companies this was often linked to the capacity to modify or reorient their market strategy through 'probe-and-learn' processes that typify the iterative nature of innovation in the MDT industry [7]. This was emphasized by several cases in which adoption by practitioners or end users in clinical practice often served as the beginning of an iterative process of refinement and improvement and as a precursor to selling in the early market.

Further downstream in the value chain the demands of the marketing process meant that the product companies needed to access the relevant management and marketing capabilities and in some cases sufficient resources to sustain a delayed market entry process. Unlike new and approved pharmaceutical products that are perhaps more likely to be accepted by the market, the MDT case studies showed that those companies involved in the development and commercialization of highly innovative and technology-intensive products faced additional marketing challenges, particularly those companies seeking to introduce discontinuous innovations or disruptive technologies [15, 25-27, 29]. Marketing strategies, allied to the recruitment of senior-level marketing and sales expertise that was well networked to the target market, were frequently based on a differentiated approach to targeting early and mainstream customers $[\mathbf{2 7}, \mathbf{2 9}]$. Their approach has been to demonstrate early competitive advantage and to establish leadership in niche markets that can be used as a broader operational base. Their approach also sought to establish relationships and 
collaborations with change agents or KOLs to expedite the route to end users and the mainstream market (practitioners in clinical practice) and which often served as the beginning of an iterative process of refinement and improvement of their products. Many of these activities were aimed towards gaining important information, sharing cost, analysing the market, and responding to market demand [15].

These exploratory findings call for further investigation. In considering strategic approaches for creating value in the MDT sector, there is a need to recognize the heterogeneity of MDT companies and the distinctive features of the MDT innovation process to understand better their influence on the commercialization process, particularly the transitions that determine access to financial and consumer markets [15]. Building on the present authors' [30] parallel study that has described a generic highlevel route map for health-care companies attempting to navigate the business growth trajectory, it is necessary to develop lower-level route maps to identify and assess the requirements for success during different phases of product development and organizational growth within the different parts of the MDT industry. It is necessary to contrast these with other parts of the health-care industry (namely the pharmaceutical and biotechnology developers) in order to help new MDT companies to recognize and understand the differences in the value trajectory for stakeholders, particularly the investors, policy makers, and health-care-related decision makers in today's device industry $[\mathbf{1 6}, \mathbf{3 1}, \mathbf{3 2}]$.

\section{ACKNOWLEDGEMENTS}

The authors thank Dr Alan Quirk for his contributions to collecting the data on which this work is based. They would also like to thank all those interviewed for their frank response to questioning.

\section{REFERENCES}

1 Whitmore, E. Unique challenges in medical product development. In Development of FDA-regulated medical products, 2004, pp. 3-33 (ASQ Quality Press, Milwaukee, Wisconsin USA).

2 Association of British Healthcare Industries. CoMapII - a competitive analysis of the healthcare industry in the UK, 2001 (ABHI Publication, London).

3 van der Walde, L. and Choi, K. Health care industry market update: medical supplies and devices, Centers for Medicine and Medicaid
Services, Office of Research, Development and Information, October 2002, available from http:// www.cms.hhs.gov/CapMarketUpdates/Downloads/ hcimu101002.pdf.

4 Gelijns, A. C. and Rosenberg, N. The dynamics of technological change in medicine. Health Affairs, 1994, 13(3), 22-46.

5 Wright, D. Medical devices on trial. In Medical device technology, Part 1, December 2002, available from www.medicaldevicesonline.com.

6 Appelt, P. and Hauser, T. Prescribing innovations: A practical framework for effective marketing of medical device innovations. J. Med. Mktg, 2006, 6(3), 195-202.

7 Gelijns, A. C. Comparing the development of drugs, devices and clinical procedures. In Institute of Medicine, medical innovation at the crossroads: modern methods of clinical investigation (Ed. A. C. Gelijns), 1990, pp. 147-201 (National Academy Press, Washington, DC).

8 Gillis, S. Factors for success in biotechnology: then and now. Nature, Biotechnol., 1998, 16, 9-10.

9 Mangematin, V., Lemarie, S., Boissun, J.-P., Catherine, D., Corolleur, F., Coronini, R., and Trommetter, M. Development of SME's and heterogeneity of trajectories: the case of biotechnology in France. Res. Policy, 2003, 32, 621-638.

10 Rautiainen, T. Critical success factors in biopharmaceutical businesses: a comparison between Finnish and Californian businesses. TEKES Technol. Rev., 2001, 113, 1-23.

11 Forbes, T. and Low, G. Strategy characteristics and biotechnology: observations from the Scottish biotechnology sector. Int. J. Entrepreneurship Innovation, 2004, 5(3), 179-190.

12 Whittle, N. Entrepreneurial business models in the UK biotechnology sector. Dissertation for Master of Business Administration Degree, Judge Institute of Management, University of Cambridge, UK, 2002, available from http://www.jims.cam.ac.uk/library/ catalogues/.

13 Williams, D. J. and Hourd, P. C. Business models and leadership styles in small medical device and bio-science businesses - examples in a region and their implications. In Proceedings of the Engineering in Medicine and Biology Society, 2004 (IEMBS '04), 26th Annual International Conference of the IEEE, 2004, vol. 7, pp. 5131-5134 (IEEE, New York).

14 Penson, S. Barriers to the innovation and commercialisation of materials-based medical devices. Report by the Biomaterials Partnership of LGC for the DTi, May 2003, pp. 1-28 (LGC Ltd, Teddington, UK).

15 Pellikka, J. and Lauronen, J. Fostering commercialisation of innovation in small high technology firms. Int. J. Technoentrepreneurship, 2007, 1(1), 92-108.

16 Better health through partnership: a programme for action, Healthcare Industries Task Force (HITF) report, November 2004, available from http://www. abhi.org.uk/multimedia/downloads/2007/HITF.pdf. 
17 Porter, M. E. How competitive forces shape strategy. In On competition, 1998, pp. 21-38 (Harvard Business School Press, Boston, Massachusetts).

18 Druilhe, C. and Garnsey, E. Do academic spinouts differ and does it matter? J. Technol. Transfer, 2004, 29(3-4), 269-285.

19 Garnsey, E., Stam, E., Hefferman, P., and Hugo, 0. New firm growth: exploring processes and paths, ERIM report series research in management reference No. ERS-2003-096-ORG, Erasmus Research Institute of Management, Rotterdam, 2003, available from http://ssrn.com/abstract $=496706$.

20 The Pan European Mediscience Review, 2002 (Deloitte \& Touche Life and Health Sciences, Cambridge).

21 Brown, J. and Higgins, N. UK biotechnology industry, twelfth report of session 2002-3 (HC87), Select Committee on Trade and Industry, Ernst and Young, 2003, pp. 486-510, available from http://www. publications.parliament.uk/pa/cm200203/cmselect/ cmtrdind/cmtrdind.htm.

22 Bains, W. and Evans, C. The business of biotechnology. In Basic biotechnology, 2nd edition (Eds C. Ratledge and B. Kristiansen), 2001, ch. 12 (Cambridge University Press, Cambridge).

23 Creating a valuable business. In Institute of Directors Briefings, ST17, BHP Information Solutions Ltd, London, 2001, available from http:// www.iod.com/.

24 Bullock, M. Academic enterprise, industrial innovation and the development of high technology financing in the United States, 1983 (Brand Brothers, London).

25 Rogers, E. M. Diffusion of innovations, 1962 (The Free Press, New York).

26 Christensen, C. M. The innovator's dilemma: when new technologies cause great firms to fail, 1997 (Harvard Business School Press, Boston, Massachusetts).

27 Moore, G. A. Crossing the chasm: marketing and selling technology products to mainstream customers, 2nd edition, 1998 (Capstone Publishing, West Sussex, UK).

28 Shane, S. and Stuart, T. Organisational endowments and the performance of university start-ups. Managmt Sci., 2002, 48(1), 154-170.

29 Costa, C., Fontes, M., and Heitor, M. V. A methodological approach to the marketing process in the biotechnology-based companies. Ind. Mktg Managmt, 2004, 33, 403-418.

30 Hourd, P. C. and Williams, D. J. Success in healthcare technology businesses: coordinating the value milestones of new product introduction, financial stakeholders and business growth. Innovation: Managmt Policy Practice, 2006, 8(3), 229-247.

31 Burns, L. R. Growth and innovation in medical devices: a conversation with Stryker chairman John Brown. Health Affairs, 2007, 26(3), 436-444.

32 O'Donnell, C. Innovation in medical technology global reality and UK promise. First UK Focus for Biomedical Engineering Annual Lecture, Royal Academy of Engineering, November 2005. 